\title{
Phonological awareness training and reading gains in a child with Williams Syndrome: a case report
}

Solange de Freitas Branco Lima(1)

Alessandra Gotuzo Seabra ${ }^{(2)}$

Luiz Renato Rodrigues Carreiro(2)

Tally L. Talfa(1)

Daniela Soares Gonzales Faria(1)

Maria Cristina Triguero Veloz Teixeira(1)

\author{
Universidade Presbiteriana Mackenzie, \\ São Paulo, São Paulo, Brasil. \\ (2) Universidade Presbiteriana \\ Mackenzie, Centro de Ciências \\ Biológicas e da Saúde, São Paulo, São \\ Paulo, Brasil.
}

Research carried out at the Development Disorders Postgraduation Program with the São Paulo Mackenzie Presbyterian University.

Research support source: This study was financed in part by the Coordenação de Aperfeiçoamento de Pessoal de Nível Superior - Brasil (CAPES) and by the Programa de Excelência Acadêmica da CAPES (PROEX).

Conflict of interests: Nonexistent

Cc)
Received on: July 3, 2018
Accepted on: October 22, 2018
Corresponding address:
Tally Lichtensztejn Tafla
Programa de Pós-Graduação em Distúrbios
do Desenvolvimento - Universidade
Presbiteriana Mackenzie
Rua da Consolação 896. Prédio 28,
$1^{0}$ andar - Consolação
CEP: 01302-000 - São Paulo, São Paulo,
Brasil
E-mail: tafla.tally@gmail.com

\section{ABSTRACT}

Williams syndrome is a neurodevelopmental disorder with different manifestations caused by a heterozygous segmental deletion of $1.55-1.83 \mathrm{Mb}$ at chromosomal band 7q11.23. The Williams syndrome phenotype is characterized by intellectual deficiency and expressive learning deficits, with impairments in phonological awareness skills. The aim of the study was to verify the effects of an intervention in phonological awareness and grammar teaching, for the acquisition of reading skills and literacy indicators in a child with Williams Syndrome. A case of a 6-year old girl, enrolled in the first year of Elementary School, was reported. The Phonological Awareness Test by Oral Production, the Words and Pseudo-words Reading Competence Test, the Provinha Brasil (reading test), and a Phonological Awareness Literacy Software, were used for phonological awareness and grammar teaching intervention. The study was developed in four phases: pre-intervention assessment, intervention, post-intervention assessment and follow-up, after six months. The results showed progress in phonological awareness skills, mainly in tasks of rhyme, alliteration and syllabic synthesis, as well as reading indicators that were compatible with the school year, following the intervention.

Keywords: Williams Syndrome; Child; Phonological Awareness; Schools 


\section{INTRODUCTION}

At preschool ages, children learn the rules of oral language through their use, without the need of formal instruction to acquire these skills ${ }^{1}$. The development of reading and writing skills must occur in the first two years of schooling. To learn to read and write in an alphabetic language, it is necessary for the child to understand rules of that language, understand the links between phonemes and graphemes, learn to segment the spoken language into distinct units and notice that these units reappear in different words, related aspects to phonological awareness ${ }^{1}$. One of the bases for understanding and mastering the alphabetic principle is the establishment of correspondences between letters and sounds, which is one of the facilitating conditions for learning to read and write in an alphabetical orthography ${ }^{2,3}$. These correspondences are part of the domain of phonological awareness skills (PA), that essentially allow the child to reflect on the sound structure of spoken words, and can manipulate their components ${ }^{4}$.

As in neurotypical development, in children with intellectual disabilities (ID), the acquisition of PA skills is essential for learning to read and write. The testing of pedagogical procedures that stimulate PA and other precursor of reading and writing skills in people with ID is necessary, since the acquisition of these will depend, in addition to the degree of intellectual commitment, on the level of stimulation. Previous studies have shown that, when PA stimuli and teaching of grammatical correspondences are introduced during literacy, children with ID and children with neurotypical development who have severe literacy gaps have shown improvements in skills to discriminate and manipulate speech segments, in the knowledge of letter-sound correspondences and in grapheophonemic decoding, as well as in reading and writing ${ }^{5,6}$.

Williams syndrome (WS) is a neurodevelopmental disorder with multi-systemic manifestations caused by a heterozygous segmental deletion of $1.55-1.83 \mathrm{Mb}$ at chromosomal band $7 q_{11.23^{7}}$. The syndrome is a rare disease, with an estimated incidence of 1: 20,000 live births and prevalence rates of approximately 1 : $7.500^{8}$. The cognitive phenotype of people with WS is characterized by cognitive, learning, communication and language deficts. In the neurocognitive development indicators, in addition to ID, are related hyperacusis, developmental delays and global deficits in executive functions, such as inhibition control, working memory and sustained attention ${ }^{9}$. In addition to these characteristcs, individuals with WS show a distinct cognitive and language phenotype characterized by contrasts and asymmetries between cognitive, language and communication skills. Mervis et al. ${ }^{10}$ named these contrasting characteristics as 'peaks and valleys profile'.

People with WS, compared to other clinical groups with ID, present some indicators of expressive language skills preserved in terms of elaborated vocabulary and the naming of objects and actions, besides some skills to learn phonetically similar words ${ }^{10,11}$. However, they also present other impairments in language and communication skills, such as language acquisition delays, disfluencies, hesitations, repetitions, discontinuities and ruptures during the speech, with impairments in structural components and speech content ${ }^{12}$.

Previous studies compared PA skills in clinical groups with ID of genetic cause such as Down syndrome (DS) and WS, showing impairment in these skills ${ }^{11,13}$. Menghini et al. ${ }^{14}$ compared the performance of adolescents and youths with WS and control group, matched by mental age, in metaphonological tasks (e.g. word segmentation, alliteration, syllabic detection and rhyme). The results showed that individuals with WS scored lower than control in some PA skills, such as rhyme detection and syllabic subtraction, as well as grapheme-phoneme conversion, and found minor impairments in lexical reading skills, which depend less on $\mathrm{PA}^{14}$.

A Brazilian research also revealed that, even in late school grades, students with WS remain with low levels of $\mathrm{PA}^{15}$. In the study, 22 students with WS, from $1^{\text {st }}$ to $8^{\text {th }}$ grades were assessed with PA and intelligence tests. Students with WS scored lower in nine of ten subtests of the PA test, compared to standard scores for children with same age and education level. In fact, 21 from 22 WS students, had "very low" PA classification, in comparison to students with typical development. Importantly, there were no significant correlations between PA, age and school grades, suggesting difficulties in phonological awareness in WS despite schooling.

Another study comparing children with WS with control group, as well as children with DS, showed that WS children produced more complete sentences (in terms of vocabulary size), in a pattern similar to children with typical development. An interesting finding in the WS group was their good performance in repetitive tasks, suggesting that short-term phonological memory skills are relatively preserved ${ }^{16}$. Thus, the studies 
cited suggest a specific profile of difficulties in PA and reading by letter-sound conversion in WS, despite lexical linguistic skills and other preserved phonological skills. For this reason, it is necessary to evaluate and implement interventions that focus on such skills as early as possible.

The effectiveness of a PA training was tested in three Brazilian children with WS aged between 9 to 11 , who attended school for more than three years ${ }^{15}$. In this study, the post-intervention raw scores showed some gains in the phonological awareness test, but the children's classification remained the same as the pre-intervention phase, which was the very low range. The study predicted the use of the On-Line Reading and Writing Battery (BALE On-Line) to evaluate word reading, however, none of the three children performed the test due to the lack of skills that are evaluated in this instrument ${ }^{15}$. There are few studies of phonological intervention in children with Williams syndrome in the first year of schooling. Considering the importance of phonological awareness for the acquisition of reading and writing, as well as the shortage of studies that verify the effect of PA training and graphophonemic teaching in younger children with WS, the aim of this study was to verify the effects of a phonological awareness training, in parallel to schooling, in the acquisition of reading skills and literacy indicators in a child with WS.

\section{CASE REPORT}

The study followed an experimental design of repeated measures to test the effect of a PA training on reading skills and literacy indicators. A case of a 6-year old girl, with molecular genetic diagnosis of WS, enrolled in the first year of Elementary Public School in the city of São Paulo, was reported. The inclusion criteria were molecular diagnoses of Williams syndrome and computer management skills. The research was approved by the Ethics Committee of the Universidade Presbiteriana Mackenzie. 1280/09/2010 and CAAE no 0088.0.272.000-10.

The study was conducted in 4 stages, Pre-intervention assessment, Intervention, Post-Intervention assessment and Follow-up, named: Phase A, Phase B, Phase C and Phase D, respectively. For the definition of intellectual functioning and receptive language skills were used the Columbia Mental Maturity Scale $(\mathrm{CMMS})^{17}$ and the Peabody Picture Vocabulary Test (PPVT) ${ }^{18}$. In addition, an audiometric assessment was performed on the child by a speech therapist. The CMMS showed a mental age of four years and nine months old, indicating a two-year delay in relation to the chronological age. In the Peabody Picture Vocabulary Test, the child presented a 5-year old compatible receptive vocabulary. In the audiometric evaluation, performed by the speech therapist, the results were in the normal range.

\section{Materials}

a) The Phonological Awareness Test by Oral Production (PAT): assesses PA skills. It consists of 40 questions divided into 10 blocks with four items each. The blocks evaluate syllabic and phonemic synthesis skills, syllabic and phonemic analysis, rhyme, alliteration, syllabic and phonemic segmentation, and syllabic and phonemic transposition. The results are presented as score or frequency of answers, with a maximum of 40 correct answers ${ }^{19}$.

b) Words and Pseudowords Reading Competence Test (WPRCT) $)^{20}$ : evaluates the stage of reading and writing development, according to the stages: i) logographic (the child sees the text as if it were a drawing, and does not recognize words); ii) alphabetic (or phonological route - the child learns the principle of decoding reading and writing coding); iii) orthographic (or lexical route - the child understands that there are words that involves irregularities in the relations between graphemes and phonemes and reads by recognition of the orthographic form). The test contains eight training items and 70 test items, consisting of seven types of randomly distributed figure/word pairs with 10 items for each test:

- Type 1 - Correct Regular - CR (orthographically and semantically correct and grapho-phonemically regular - eg, the word FADA (fairy in english) written word and the corresponding picture);

- Type 2 - Correct Irregular - Cl (words spelled correctly and semantically correct and gramophonically irregular, eg TAXI and the corresponding picture);

- Type 3 - Semantic changes - SC (words spelled correctly and semantically incorrect: eg RÁDIO (radio in english) under the picture of a telephone, item that does not correspond to the word);

- Type 4 - Visual changes - VC (orthographically incorrect words, with visual changes), eg TEIEUISÃO (a word that does not exist, and the correct way to write it in Portuguese is TELEVISÃO (television in english)) with the picture of a television;

- Type 5 - Phonological changes - PC (orthographically incorrect words, with phonological changes), 
eg the word 'MÁCHICO' (a word that does not exist, and the correct way to write it in Portuguese is MÁGICO (magic in english)) on the figure of magic;

- Type 6 - homophone non-words - HN (non-words orthographically incorrect, although homophones to semantically correct words), eg JENIU (a word that does not exist, and the correct way to write it in Portuguese is GÊNIO (genius in english)) with the picture of a genius);

- Type 7 - weird non-words (non-words spelled incorrectly and strangely, both phonologically and visually), eg MELOCE (a word that does not exist in Portuguese) on the figure of a clown.

The instrument provides standard scoring tables, with performance rating in: 'below 70 - very low'; 'Between 70 and 84 - low'; 'Between 85 and 114 medium'; 'Between 115 and 129 - high'; 'Equal to or greater than 130 - very high'.

c) Provinha Brasil (reading test) ${ }^{21}$ : evaluates the child's level of literacy. Proposed by the Ministry of Education (MEC), it is recommended for students of the $2^{\text {nd }}$ year of Elementary School. It is divides into two parts: the first part evaluates the ability to recognize letters and syllables, to establish a relation between sound units and their graphic representations. The second part evaluates the ability to read words and phrases, recognize, identify and establish information in the text. The material contains the correction/ interpretation guide and the application guide, which consists of a student application notebook with 20 multiple choice questions with four alternatives each. The questions are divided into 3 types and the classification of the students' performance levels can be: Level 1 - up to 4 correct answers; Level 2 - from 5 to 9 correct answers; Level 3 - from 10 to 15 correct answers; Level 4 - from 16 to 18 correct answers; Level 5 - from 19 to 20 correct answers.

d) Phonological Awareness Literacy Software. This software was elaborated by Seabra, Capovilla and Macedo $^{22}$ to develop PA competencies and grafophonic correspondences in a child. The knowledge of the alphabet activities covered the sounds of letters, beginning with vowels and then with consonants, subdividing them as follows: i) vowels with only one sound; (ii) vowels with more than one sound; and (iii) consonants with greater difficulty of pronunciation in the sequence (e.g. F, J, M, N, V, Z, I, S, R, X, B, C, P, $D, T, G$, and $Q, H)$. The PA activities included: i) words (to complete sentence and replace non-words); ii) rhymes (rhymes judgment); iii) syllables and phonemes (counting, addition, subtraction and transposition). All activities were performed after software instructions were offered.

In phases $A, B, C$ and $D$ was used the Phonological Awareness Test by Oral Production (PAT) ${ }^{19}$. In phase $D$, two new instruments were added to test the reading level of the child after the PA training. They were: the Words and Pseudowords Reading Competence Test ${\text { (WPRCT })^{20} \text { and Provinha Brasil }}^{21}$, both for evaluation of reading skills. They were not part of the assessment in phases $A, B$ and $C$ for the following reasons: a) Words and Pseudowords Reading Competence Test (WPRCT) was not applied due to the student's low reading performance, according to the child's school records; b) Provinha Brasil was not applied because it is a recommended instrument for students of the $2^{\text {nd }}$ year of Elementary School.

\section{Intervention}

Phonological awareness and graphophonemic correspondences intervention were performed in 24 sessions, applied twice a week for 3 months, in the school where the child was enrolled and in a private room, under the control of distracting stimuli. The school authorized the student to participate in this study without compromising her activities at regular class. The training room contained a table, two chairs and a notebook computer (model HP mini 210-1020BR). The intervention was conducted using the Phonological Awareness Literacy Software ${ }^{22}$. Each session of stimulation lasted 30 minutes and, right after the intervention, the child was taken back to the classroom. The 24 intervention sessions were divided into two stages of 12 sessions each. In the first stage, the researcher encouraged the child to think about the sounds of words, syllables and phonemes proposed by the software; in the second stage, the researcher asked the child to perform the tasks proposed by the software without providing support or assistance.

Descriptive analyzes were conducted using simple tables. The PAT data were analyzed comparatively in relation to the pre and post phases in terms of the number of scores and errors. The data from the WPRCT and Provinha Brazil results were analyzed comparatively in relation to normative data.

\section{RESULTS}

In PAT, there was an increase in the number of successful phonemic synthesis' test (from 1 in phase $A$ 
to 2 in phase D), in the rhyme test (from 1 hit in phase A to 3 in phase $D$ ) and in the syllabic segmentation test (from 0 to 4 hits in phase $C$, but returned to 0 in phase D). In syllabic synthesis, the child maintained the same number of correct answers (4) in all phases of the study (Table 1). The child's total scores were compared to normatization to children with typical development. In Phase A, the child had a PA total score that is expected from 4,5 years-old students. After the 3-months intervention, in Phase 3, her total score improved to a 5,5 years-old students range. In terms of classification, her score in Phase A was considered "Low" (standardized score $=74$ ) and in Phase 3 , with the gain, the score had a range classification as "Average" (standardized score $=88$ ).

Table 1. Results of Phonological Awareness Test by oral production (PAT) obtained during the study phases

\begin{tabular}{|c|c|c|c|c|c|}
\hline \multicolumn{2}{|c|}{ PAT } & Phase A & Phase B & Phase C & Phase D \\
\hline \multirow{2}{*}{ Synthesis } & Syllabic & 4 & 4 & 4 & 4 \\
\hline & Phonemic & 1 & 1 & 1 & 2 \\
\hline \multicolumn{2}{|c|}{ Rhyme } & 1 & 0 & 1 & 3 \\
\hline \multicolumn{2}{|c|}{ Alliteration } & 0 & 0 & 1 & 1 \\
\hline \multirow{2}{*}{ Segmentation } & Syllabic & 0 & 0 & 4 & 0 \\
\hline & Phonemic & 0 & 0 & 0 & 0 \\
\hline \multirow{2}{*}{ Manipulation } & Syllabic & 0 & 0 & 1 & 0 \\
\hline & Phonemic & 0 & 0 & 0 & 0 \\
\hline \multirow{2}{*}{ Transposition } & Syllabic & 0 & 0 & 1 & 0 \\
\hline & Phonemic & 0 & 0 & 0 & 0 \\
\hline Total & & 6 & 5 & 13 & 10 \\
\hline
\end{tabular}

The reading tests (WPRCT and Provinha Brasil) applied in phase $\mathrm{D}$ are shown in Table 2. The highest number of correct answers was found in the words IC (words spelling and semantically correct, but gramophonically irregular) with a standard score of 110.55 . According to the norms of the test, in relation to the school year, the child classified in the average range in all types of items and in the global score, except for the item "Weird Non-words", in which she obtained the worst performance, with a score standard of 55.62 and classification "Very low".

Table 2. Results of the raw score, standard score and classification obtained in the Words and Pseudowords Reading Competence Test in phase $\mathrm{D}$

\begin{tabular}{|c|c|c|c|c|c|c|c|c|}
\hline \multirow{2}{*}{ WPRCT } & \multicolumn{8}{|c|}{ Sub-items of the test } \\
\hline & $\mathrm{RC}$ & IC & SC & VC & PC & HN & WN & Total \\
\hline Raw Score & 7 & 8 & 7 & 6 & 6 & 6 & 3 & 43 \\
\hline $\begin{array}{l}\text { Standard } \\
\text { Score }\end{array}$ & 95.42 & 110.55 & 88.89 & 95.13 & 98.15 & 103.16 & 55.62 & 90.33 \\
\hline Rating & Average & Average & Average & Average & Average & Average & Very Low & Average \\
\hline
\end{tabular}

Captions: WPRCT: Words and Pseudowords Reading Competence Test; RC: Regular Correct; IC: Irregular Correct; SC: Semantic Changes; VC: Visual Changes; PC: Phonological Changes; HN: Homophone Non-words, WN: Weird Non-words. 
In order to verify indicators of children's literacy, Provinha Brasil was applied, in which it obtained a Level 3 of classification (10 scores of 20 questions). This indicates, according to the description of the test ${ }^{21}$, that the child showed reading abilities for sentences with simple syntax but that still does not know how to read words of different patterns.

\section{DISCUSSION}

Oral and written language skills influence each other ${ }^{2,5}$. The PA, in terms of the ability to segment and analyze sound units, is essential for learning to read and write, allowing the child to manipulate sounds that are related to letters. In the present study, in a PA and graphophonemic intervention performed by a child with WS, it was observed that, in general, the child presented an increase in the number of scores in the PAT from Phase A to Phase C, except for the follow up test, when it returned to score 10 in phase $\mathrm{D}$. One hypothesis may be that, due to the cognitive profile of the syndrome (with ID indicators and inattention), it is likely that the effect of the intervention has diminished over time. However, in general, the PAT results suggest that the intervention, associated to schooling, although it did not bring expressive results in all the subtests of the test, it still seems to have contributed positively to the improvement of the child's performance in some tasks of phonological awareness. This fact is relevant since this metaphonological ability does not develop naturally, only with exposure to linguistic stimuli, as occurs with oral language, but it needs formal instructions ${ }^{19}$.

Although the study design does not permit to estimate precisely which gains are consequence of schooling and which ones are consequence of the intervention, it is possible to offer some explanations. Firstly, previous research in Brazil, with the same PA test and in public school, showed that PA performance in students with SW remains very low despite schooling, even in late grades ${ }^{15}$. That is, only scholar instructions do not seem enough to minimize differences between students with typical development and with WS. Secondly, the observed gains exceeded the expected gains due only to schooling. The child had an improvement of 1 year in terms of her total PA score, and her classification range changed from "low" to "average". This analysis can reinforce the majority effect of specifically intervention to PA in relation to regular schooling.
In terms of each subtest, in the syllabic synthesis test, the child has already been successful in all the items since phase $\mathrm{A}$, confirming that this ability had already been acquired, as has been reported in children with typical development who develop skills in syllabic synthesis at preschool age ${ }^{19}$. In the tasks of judgment of rhymes and alliterations, in which the participant needed to identify words that began and ended with the same sound, a small increase of the scores was observed. In the tasks of manipulation and transposition syllabic, we observed an increase of 1 point in phase $C$, but zero in phase $D$. We can hypothesize that the success in phase $C$ was casual, that the error in phase $D$ was due to inattention or fatigue, or that the effect of training decreased over time. Finally, in the more complex tasks related to phoneme awareness, namely, segmentation, manipulation and transposition, the student did not achieve any success in any of the phases. They are usually skills that are acquired later, simultaneously or even after literacy ${ }^{19}$. In the test's total, an important increase was observed between Phase $A$ (6 scores) and $C$ (13 scores), with a decrease in the last phase (10 scores). The previous study by Segin et al. ${ }^{15}$ obtained similar results.

The data obtained in the WPRCT indicate that the child has abilities to read isolated items in the middle range, according to the norm for the educational level. The best indicators were verified in tasks with regular and irregular correct words, semantic and phonological changes, homophones non-words, with lowered performance in weird non-words. The data indicate that the child has abilities to recognize words and non-words, although at different levels, because the results, even though in the middle range (standard score between 85 and 115), varied among the items. It is interesting that the child's worst performance was in an item considered easy according to the norms of the test (Weird Non-words). In this element the student tended to indicate as "correct" the pair of words in which the figure is followed by a completely strange name (e.g. written word MELOCE in the picture of a clown). Such behavior may suggest that, when the student did not know the written word (since it was a non-word), she tended to judge it as correct (probably attributing to herself the ignorance of the word), rather than analyzing and considering it as incorrect. Thus, in general, regarding the results of the WPRCT, the child was classified at a level of academic performance relatively adequate for her school year. In agreement with this result, the child showed an age of four years 
and nine months of intellectual functioning in the CMMS and in the Peabody Picture Vocabulary Test (PPVT), which evaluates receptive language skills, presented compatible receptive vocabulary with 5 years. However, as in the Basso's study ${ }^{23}$, the results were heterogeneous among the reading tests.

According to the results in Provinha Brazil, students who are in level 3 of classification show that they have consolidated the ability to read words of different sizes and syllabic patterns, can read simple sentences and use some strategies that allow reading short texts, identify numbers of syllables and find information in short texts or phrases. Therefore, at the end of the intervention, the child seemed to have reading skills in the expected standards for the school year in which she attends, although it is necessary to track her during schooling to see if there will be later gains, especially in view of the cognitive deficit verified in the CMMS.

The study allowed us to stimulate some repertoires of PA abilities in the child, which could possibly positively influence graphophonemic decoding, skills that are essential for reading and writing in an alphabetical orthography. The design of the present study does not allow to infer if the child's performance was or not due to the intervention and/or regular schooling, but it is emphasized that, because they are skills learned in a formal way, it can be assumed that the training is associated to the results. The results obtained in the phase A corroborate with previous findings that demonstrated phonological processing skills in SW ${ }^{11,13}$. However, if the child is adequately stimulated in school, with curriculum adaptations appropriate to their needs, which in fact was proposed to the school's educational team, an even more important improvement in the PA. In consequence the acquisition of reading and writing could be stimulated. Thus, it is likely that some of the acquired PA skills, if consistently stimulated, could be a facilitating condition for later literacy development, as shown in the study by Havy et al. ${ }^{24}$. However, it should be emphasized that the teacher should have adequate training in the area of PA skills and graphophonemic correspondences, as well as appropriate knowledge about the characteristics of the cognitive and language phenotype of the syndrome. With this, it is possible to implement pedagogical interventions adapted to the needs of the child.

\section{CONCLUSION}

From the obtained results, it can be concluded that there were progresses in some indicators of PA abilities, although these gains have been varied according to the type of skill and the moment of the evaluation. Although WS students usually show low scores in PA, despite schooling, the child in this study had a 1-year improvement in her standardized score, with a 3-month intervention. Her range classification improved from "low" to "average". Increases were observed in PA indicators from performance in tasks of rhyme, alliteration and syllabic synthesis. Other data regarding reading skills also indicated that the child in the last phase of the study showed indicators of abilities to decode words and non-words, although her levels also ranged from average to below average, expected for the age. This showed that, after the intervention, there was the presence of some important phonological processing skills, which would be a potential to be explored in the classroom context, aiming at the acquisition of reading and writing skills. Another relevant finding was Provinha Brasil. Although the instrument was only part of the study design in phase $D$, as it is a recommended instrument for students in their $2^{\text {nd }}$ year of elementary school, the performance of the child was adequate, considering that the child classified in levels of academic performance compatible for the chronological age.

The study verified the feasibility of using phonological intervention in WS. The observed gains exceeded the expected gains due to schooling alone. The child had an improvement of 1 year in terms of her total PA score, and her classification range changed from "low" to "average. The study had as limitations the absence of reading evaluation in phases $A$ to $C$ because, according to the school records, the student did not have reading skills, sothe WPRCT was not applied. Thus, the study did not verify the evolution of this measure throughout the experiment. Another limitation was schooling itself, since PA intervention and graphophonemic correspondence occurred concomitantly with the literacy process in school settings. This variable prevents full assignment of gains in PA and reading to training. However, these gains may be derived from schooling associated with intervention. It was not possible, either, to evaluate the indicators of oral motor control to assess the influence of this on speech and performance in PAT, which would be desirable for future studies.

Despite the limitations, the results of the study show that PA can be developed if properly stimulated, especially because the child has acquired not only PA skills, but also reading indicators at appropriate levels. 
It is recommended that educational public policies develop actions among children with WS contemplating the insertion of PA skills stimulation programs from Early Childhood Education, extending to the $1^{\text {st }}$ and $2^{\text {nd }}$ years of Elementary School, in parallel to the teaching of the graphophonemic correspondences, to verify the effect on reading and writing skills and learning of specific knowledge.

\section{REFERENCES}

1. Santos MJ, Barrera SD. Impacto do treino em habilidades de consciência fonológica na escrita de pré-escolares. Psicol.Esc. Educ. 2017;21(1):93-102.

2. Cardoso-Martins $\mathrm{C}$, Frith U. Consciência fonológica e habilidade de leitura na síndrome de down. Psicol. Reflex. Crit. 1999;12(1):209-24.

3. Barrera SD, Santos MJ. Influência da consciência fonológica na aprendizagem da leitura e escrita: o que dizem as pesquisas brasileiras. In: Oliveira JP, Braga TMS, Viana FLP, Santos AS (orgs). Alfabetização em países de língua portuguesa. 1a ed. Curitiba: CRV; 2014. p.27-41.

4. Carvalho IAM, Alvarez RMA. Aquisição da linguagem escrita: aspectos da consciência fonológica. Fono Atual. 2000;1(11):28-31.

5. Capovilla AGS, Capovilla FC. Problemas de leitura e escrita: como identificar, prevenir e remediar numa abordagem fônica. 6a ed. São Paulo: Memnon; 2010.

6. Justino MISV, Barrera SD. Efeitos de uma intervenção na abordagem fônica em alunos com dificuldades de alfabetização. Psic.: Teor. e Pesq. 2012;28(4):399-407.

7. Mervis $\mathrm{CB}$, Velleman SL. Children with Williams syndrome: language, cognitive, and behavioral characteristics and their implications for intervention. Perspect. Lang. Learn. Educ. 2011;18(3):98-107.

8. Strømme P, Bjørnstad PG, Ramstad K. Prevalence estimation of Williams syndrome. J Child Neurol. 2002;17(4):269-71.

9. Mervis CM, John AE. Cognitive and behavioral characteristics of children with Williams syndrome: implications for intervention approaches. Am J Med Genet C Semin Med Genet. 2010;154C(2):229-48.

10. Mervis CB, Robinson BF, Rowe ML, Becerra AM, Klein-Tasman BP. Language abilities in Individuals with Williams syndrome. In: Abbeduto $L$ (org). International review of research in mental retardation. Orlando, FL: Academic Press; 2003. p. 35-81.

11. Steele A, Scerif G, Cornish K, Karmiloff-Smith A. Learning to read in Williams syndrome and Down syndrome: syndrome-specific precursors and developmental trajectories. J Child Psychol Psychiatr. 2013;54(7):754-62.

12. Diez-Itza E, Martínez V, Pérez V, Fernández-Urquiza $M$. Explicit oral narrative intervention for students with Williams syndrome. Frontiers in Psychology. 2017;8:2337.

13. Majerus S, Barisnikov K, Vuillemin I, Poncelet M, Linden MVD. An investigation of verbal short-term memory and phonological processing in four children with Williams syndrome. Neurocase. 2003;9(5):390-401.

14. Menghini D, Verucci L, Vicari S. Reading and phonological awareness in Williams syndrome. Neuropsychology. 2004;18(1):29.

15. Segin M, Dias NM, Seabra AG, Teixeira MCTV, Carreiro LRR. Phonological awareness assessment in Williams syndrome. Rev. CEFAC. 2015;17(5):1483-90.

16. Volterra VM, Caselli C, Capirci O, Francesca T, Vicari S. Early linguistic abilities of italian children with Williams syndrome. Developmental Neuropsychology. 2011;23(1-2):33-58.

17. Alves ICB, Duarte JLM. Padronização Brasileira da Escala de Maturidade Mental Colúmbia. In: Burgemeister BB, Burgemeister LH, Lorge I (org). Escala de Maturidade Mental Colúmbia: manual para aplicação e interpretação. 3 a ed. São Paulo: Casa do Psicólogo; 1993. p.24-32.

18. Capovilla FC, Capovilla AGS, Nunes L, Aráujo E, Nunes $D$, Nogueira $D$ et al. Versão brasileira do teste de vocabulário por imagens peabody: dados prelimiares. Distúrb. Comun. 1997;8(2):151-62.

19. Capovilla AGS, Capovilla FC. Prova de consciência fonológica: desenvolvimento de dez habilidades da pré-escola à segunda série. Temas desenvolv. 1998;7(37):14-20.

20. Seabra AG, Capovilla FC. Teste de competência de leitura de palavras e pseudopalavras. 1a ed. São Paulo: Memnon; 2010.

21. Brasil. Ministério da Educação. Portaria no 10 , de 24 de abril de 2007. Provinha Brasil: avaliando a alfabetização. Brasília: Instituto Nacional de Estudos e Pesquisas Educacionais Anísio Teixeira-INEP; 2007. 1. 
22. Capovilla AGS, Capovilla FC, de Macedo EC. Alfabetização fônica computadorizada: fundamentação teórica e guia para o usuário. $1^{\underline{a}}$ ed. São Paulo: Memnon; 2017.

23. Basso FP. A estimulação da consciência fonológica e sua repercussão no processo de aprendizagem da lecto-escrita [Tese]. Santa Maria (RS): Universidade Federal de Santa Maria, Programa de Pós-Graduação em Educação; 2006.

24. Havy M, Moukawane S, Nazzi T. Are 3-to-8-year-old children with Williams syndrome good word-learners? NeuroReport. 2010;21(13):882-6. 